\title{
Folk Remedies in Children and its Reflection on Child's Welfare
}

\section{Diana H Arabiat*}

Department of Maternal and Child Health Nursing, Faculty of Nursing, The University of Jordan, Amman, Jordan

The use of folk medicine versus western biomedicine has come into close contact and unfortunate conflict through out different studies. However, it has been and still is relied on by different ethnic minorities such as Southeast Asian, African, Middle Eastern and Hispanic groups [1-4]. Folk medicine practices consists of alternative practices and therapies including herbs, food products, ritualistic behaviors or household items that are recommended by members of the lay community or religious group. Folk medicine remains a popular choice for some minorities for many reasons, including health beliefs, lack of professional care, economic factors and its availability [3-5]. The use of folk medicine for children is also documented. The growing number of children exposed to unproven methods of healings, and their vulnerability make it imperative that child welfare and health care workers understand folk-healing practices if they are to provide appropriate and culturally sensitive services.

The use of folk remedies is attributable to differences in the beliefs and values about health and illness between different societies. Those beliefs and practices eventually have become part of each society traditions and culture. While Western medicine is commonly used worldwide, each society has retained ethno medical beliefs and practices that differ dramatically from those of scientific health care. In African American for example, one of the remedies for fever is having a child wear sliced potatoes or onions in his/her socks as to draw the impurities out of the body through the soles of the feet [5]. Whereas, in the Arab world, tying pieces of garlic on a string around an infant's neck is practiced to treat jaundice. Those healing intervention have its own validity and integrity within each community, however, utilizing folk remedies in these communities might be interpreted by the western societies as ignorance, superstition, or simply as abuse.

The fact that the benefits of folk medicine remain largely debatable and unproven has led to closer scrutiny of the products used in traditional healing. For instance, in South Africa, a mortality rate of $40 \%$ related herbal intoxication was reported for children receiving alternative treatments [3]. The devastating effects of intoxication and the possible interaction with conventional drugs required an international effort for investigating the pharmacokinetics of herbs/ push medicine that is used in folk remedies. In addition, a proper phytochemical evaluation of selected plant species can be used for the discovery of biologically active novel chemical compounds as a starting point for the development of new drugs. However, as there is relatively limited and incomplete written information on such healing practices, there is a need to address the meaning and practices of folk medicine in children for non-western communities, in addition to understand how families made their decisions regarding the use of folk medicine or modern biomedicine in healing their child.

It is important for health care practitioners to be aware of the remedies used within each ethnic community being served, so that they can find ways to incorporate a compatible approach to them in their work. As if the practitioners in cross-cultural services do not understand traditional health beliefs and practices and find ways to incorporate a compatible approach to them in their work, some patients will go their own ways, sometimes with dire results.

Perhaps the most important message to take from previous studies is that blending of folk medicine and western biomedicine may be acceptable, as long as the folk remedies are not harmful to the patient [5]. Health care practitioner should try to incorporate folk remedies into the plan of care rather than denying the effectiveness of some of these remedies. It is important to note that each ethnic community is a hetrogenous group in terms of beliefs and practices. Thus we can't assume that all ethnic minorities practice folk healing. However, we should bear in mind the great need for additional research in folk healing practices, especially for children. There is a gap in literature related to some ethnic groups, such as Arabs' use of folk medicine and the values associated with it in the context of child health care. It is not known what folk beliefs contest with the biomedical etiologies or treatments, and thus how folk beliefs may influence child's welfare mainly by interfering with early access to child health care services or adherence to treatment regimens. Until such research is conducted, health care professionals treating children of ethnic minorities should be sensitive to the prevalence of alternative healing practices which may affect the child's welfare and attempt to integrate their medical treatments into a culturally appropriate model.

\section{References}

1. Mikhail BI (1994) Hispanic Mothers' Beliefs and Practices Regarding Selected Children's Health problems. Western Journal of Nursing Research 16: 623-638.

2. Risser AL, Mazur LJ. (1995) Use of folk remedies in a Hispanic population. Archives of Pediatrics and Adolescent Medicine 149: 978-981.

3. Dambisya YM and Tindimwebwa G (2003) Traditional remedies in children around Eastern Cape, South Africa. East African Medical Journal. 80: 402-405.

4. Arabiat D, Al Jabery M, Abed-alqader R, Mahadeen A (2013) Jordanian Mothers' Beliefs about the Causes of Cancer in Their Children and Its impact on the Maternal Role. Journal of Transcultural Nursing 24: 246-253.

5. Smitherman LC, Janisse J, Mathur A (2005) The use of folk remedies among children in an urban black community: Remedies for fever, colic, and teething Pediatrics. 115: 297-304

*Corresponding author: Diana $\mathrm{H}$ Arabiat, Department of Maternal and Child Health Nursing, Faculty of Nursing, The University of Jordan, Amman, 11942 Jordan, Tel: 96265355000/23182; 9627774438538; E-mail: d.arabiat@ju.edu.jo, dnarabiat@yahoo.co.uk

Received December 09, 2013; Accepted December 10, 2013; Published December 15, 2013

Citation: Arabiat DH (2014) Folk Remedies in Children and its Reflection on Child's Welfare. Clinics Mother Child Health 11: e104. doi: 10.4172/2090-7214.1000e104

Copyright: (c) 2014 Arabiat DH. This is an open-access article distributed under the terms of the Creative Commons Attribution License, which permits unrestricted use, distribution, and reproduction in any medium, provided the original author and source are credited. 